\title{
ALTERNATIVAS DE MANEJO CONTRA EL COMPLEJO MOSCA BLANCA (Bemisia tabaci Gennadius)- GEMINIVIRUS EN EL CULTIVO DE TOMATE [Solanum lycopersicum L. = (Lycopersicum esculentum Mill.)] EN TISMA, MASAYA (2009) Y CAMOAPA, BOACO (2010)
}

\begin{abstract}
ALTERNATIVES OF MANAGEMENT AGAINST COMPLEX WHITEFLY (Bemisia tabaci Gennadius)-GEMINIVIRUS IN TOMATO [Solanum lycopersicum L. = (Lycopersicon esculentum Mill)] IN TISMA, MASAYA (2009) AND CAMOAPA, BOACO (2010)
\end{abstract}

Cerda Kelving $\mathbf{J}^{1}$. Jimenez-Martinez Edgardo ${ }^{2}$

${ }^{1}$ MSc Agroecología y Desarrollo Sostenible, Universidad Nacional Agraria Sede Camoapa; E-mail: kelvin.cerda@una.edu.ni ${ }^{2}$ Ph.D Entomología, Universidad Nacional Agraria/DPAF E-mail: edgardo.jimenez@una.edu.ni

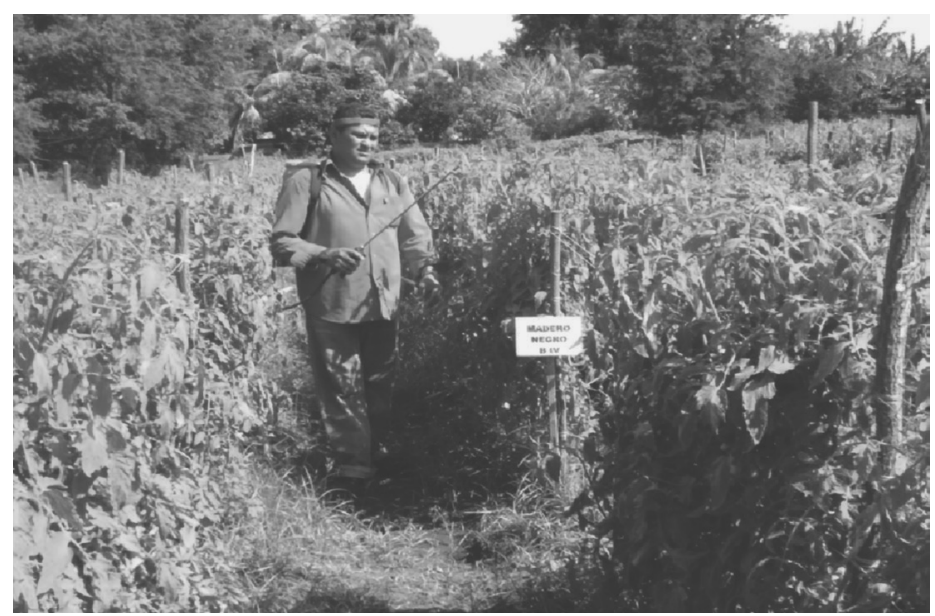

\section{RESUMEN}

Mosca blanca (Bemisia tabaci) y los Geminivirus, son un serio problema para los productores de tomate en Nicaragua, este complejo afecta drásticamente los rendimientos del cultivo. Se han reportado diferentes tecnologías como solución al problema, tales como el uso de microinvernadero en la etapa semillero, uso de insecticidas sintéticos y prácticas culturales en la etapa de campo, sin embargo, la problemática de la plaga aún persiste. Con el propósito de identificar alternativas que disminuyan el daño ocasionado al medio ambiente y que sean económicamente viables, se estableció la investigación en la que se comparo el efecto de alternativas botánicas y químicas sobre la poblaciones de adultos B. tabaci, porcentaje de incidencia de virus, porcentaje de severidad de virus, rendimientos y análisis económico. El ensayo se estableció en dos ambientes, uno en Tisma (Masaya) en el periodo de Octubre a Diciembre del 2009 y el otro en Camoapa (Boaco) en los meses de Abril a Junio del 2010. El diseño utilizado fue un bloque completo al azar (BCA) en ambas localidades, los tratamientos evaluados fueron: Actara 25 WG (Thiametoxam); Engeo 24,7 SC (Thiametoxam+Lambda-Cihalotrina); macerado de hojas de madero negro (Gliricidia sepium); aceite vegetal+jabón líquido, chile (Capsicum $s p$ ) + ajo (Allium sativum)+jabón y un testigo. Los resultados encontrados fueron los siguientes: los tratamientos con engeo, aceite vegetal + jabón líquido y hojas de madero negro registraron los promedios más bajo de mosca blanca por planta tanto en Tisma como en Camoapa. Los menores porcentajes de incidencia de virus y porcentaje de severidad del daño del virus fueron en engeo, aceite vegetal+jabón líquidos y madero negro. Los mejores rendimientos fueron registrados en engeo con promedios 26581$18953 \mathrm{~kg} \mathrm{ha}^{-1}$ y hojas de madero negro con promedios 25277-18107 $\mathrm{kg} \mathrm{ha}^{-1}$ en Tisma (2009) y Camoapa (2010) respectivamente. El

\section{ABSTRACT}

Whitefly (Bemisia tabaci) and geminiviruses, are a serious problem for tomato growers in Nicaragua, this complex affects crop yields dramatically. Different technologies have been reported as a solution to the problem, such as using microinvernadero in seedling stage, use of synthetic insecticides and cultural practices in the field stage, however, the problem still persists pest. In order to identify alternatives that reduce the damage to the environment and economically viable, established the research that compared the effect of botanical and chemical alternatives on adult populations B. tabaci, virus incidence rate, severity rate of virus yields and economic analysis. The trial was conducted in two environments, one in Tisma (Masaya) in the period from October to December 2009 and the other in Camoapa (Boaco) in the months of April to June 2010. The design was a randomized complete block (BCA) in both locations, the treatments were: Actara $25 \mathrm{WG}$ (Thiametoxam) 24.7 ENGEO SC (Thiametoxam + lambda-cyhalothrin), macerated black tree leaves (Gliricidia sepium ) + vegetable oil liquid soap, pepper (Capsicum $s p)+$ garlic (Allium sativum) + soap and a witness. The results were as follows: ENGEO treatments, vegetable oil and liquid soap + tree leaves black lowest recorded averages of whiteflies per plant both as Camoapa Tisma. The lowest percentages of virus incidence and severity of the damage percentage of virus were ENGEO, vegetable oil and liquid soap + black tree. The best yields were recorded with averages ENGEO 26581-18953 kg ha-1 and black tree leaves with averages 25,277 to $18,107 \mathrm{~kg} \mathrm{ha}^{-1}$ in Tisma (2009) and Camoapa (2010) respectively. The economic analysis showed that ENGEO presented a TRM of $457 \%$ in Tisma (2009) and 696\% in Camoapa (2010)

Keywords: natural insecticides, economic analysis. 
análisis económico demostró que engeo presentó una TRM de 457 $\%$ en Tisma (2009) y $696 \%$ en Camoapa (2010).

Palabras clave: Micro invernadero, barreras físicas, insecticidas naturales, análisis económico.

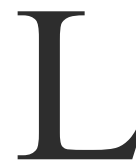

a producción de tomate [Solanum lycopersicum L. $=$ (Lycopersicum esculentum Mill.) $]$ en Nicaragua se encuentra en mano de pequeños y medianos productores, los cuales dan a conocer que su problema más sentido es el complejo mosca blanca (Bemisia tabaci, Gennadius) - Geminivirus, el cual reduce los rendimientos drásticamente (Zamora, et al., 2002). Los problemas ocasionado por el complejo mosca blancageminivirus se reportaron en Centroamérica desde 1961 y en Nicaragua por primera vez en 1965 (CATIE, 1990).

Mosca Blanca (B. tabaci) es un Hemiptera: Homoptera: Aleyrodidae, es una plaga polífaga, cosmopolita y de gran relevancia mundial sobre todo como vector de virus en numerosos cultivos (Gina, et al., 2009). Este insecto está incluido en la posición 100 de las especies exóticas invasoras más dañinas del mundo según la Unión Internacional para la Conservación de la Naturaleza (Lowe, et al., 2000). Los geminivirus pertenecen a la familia Geminiviridae (Fauquet, 2000) y se dividen en cuatro géneros Mastrevirus, Curtovirus, Topocovirus y Begomovirus; este último es transmitido por $B$. tabaci y con un numero alto de hospederos dificultando más el combate del mismo (Zúñiga y Ramírez, 2002).

Flores, et al., 2008, mencionan que $B$. tabaci, es una plaga clave de las hortalizas y otros cultivos, mundialmente representa un problema en los trópicos, debido a su habilidad para transmitir varios tipos de virus, especialmente begomovirus (Geminiviridae).

En Centroamérica se reportan los biotipos A, B y Q, con mayor prevalencia el biotipo A (Guachambala, 2007), Jiménez - Martínez (2008), reportó que en Nicaragua hay presencia de biotipos A y $\mathrm{B}$, lo que nos hace reflexionar que en el manejo se deben considerar estrategias que reduzcan poblaciones de mosca blanca con resistencia a plaguicida utilizados por los productores.

En el 2006, en el municipio de Tisma se evaluaron cuatro alternativas de manejo del complejo mosca blancageminivirus en etapa de semilleros. Los resultados de estos estudios reportan que el uso de barreras físicas como microinvernadero, protegen de manera efectiva las infecciones tempranas de virus transmitidos por mosca blanca (Rodríguez y Morales, 2007). Esta propuesta de manejo del complejo mosca blanca - geminivirus no es totalmente la solución al problema, ya que es necesario además identificar alternativas de manejo para la etapa de campo, en este periodo los productores aplican tecnologías que provocan consecuencias casi irreversibles al medio ambiente y que ponen en riesgo la salud de la población.

En la búsqueda de técnicas auto-sostenidas que ayuden a recuperar el equilibrio del agroecosistemas en cultivo de tomate, que protejan al hombre y que sea viable económicamente, se establecieron parcelas de evaluación de insecticidas químicos y botánicos para el manejo de $B$. tabaci en dos localidades productoras de tomate. Las localidades evaluadas fueron los municipios de Tisma, Masaya y Camoapa, Boaco, ambas productoras de tomate que suple parte de la demanda del pacífico y centro de Nicaragua. El propósito de la investigación fue identificar alternativas de manejo contra el complejo mosca blanca - geminivirus que contribuyan a un desarrollo sostenible en la producción de tomate en Tisma y Camoapa.

\section{MATERIALES Y MÉTODOS}

Ubicación del estudio. El estudio se realizó entre los períodos de Septiembre a Diciembre de 2009 en el municipio de Tisma, Masaya, y de Abril a Julio del 2010 en el municipio de Camoapa, Boaco.

Tisma, Masaya se ubica a $36 \mathrm{~km}$ de la ciudad de Managua capital de Nicaragua, a una altura de 50 m.s.n.m., las coordenadas son $12^{\circ} 04^{\prime}$ latitud norte y $86^{\circ} 01^{\prime}$ latitud oeste. Se caracteriza por un clima tropical de sabana, con temperaturas promedio de $27.5^{\circ} \mathrm{C}$ y precipitaciones pluviales anuales de 1200 y $1400 \mathrm{~mm}$ (AMUNIC, 2005).

Camoapa, Boaco se encuentra a $114 \mathrm{~km}$ de Managua, con una altura de 520 m.s.n.m., con coordenadas $12^{\circ} 23^{\prime}$ de latitud norte y $85^{\circ} 30^{\prime}$ de longitud oeste. Las temperaturas promedios oscilan entre $23^{\circ} \mathrm{C}$ y $25.2^{\circ} \mathrm{C}$, con precipitaciones pluviales anuales de 1,200 y 2,000 mm (INIFOM, 2011).

Diseño metodológico. Se utilizó un experimento con diseño de bloques completos al azar (BCA), dividido en cuatro repeticiones de seis parcelas (tratamientos). Las dimensiones de la parcela fueron de $6 \mathrm{~m}$ de largo por $9 \mathrm{~m}$ de ancho para un área de $54 \mathrm{~m}^{2}$, el área total de cada repetición fue de 324 $\mathrm{m}^{2}$. La distancia entre repetición fue de $2 \mathrm{~m}$, para un área entre repetición de $108 \mathrm{~m}^{2}$, el área total del experimento fue de $1620 \mathrm{~m}^{2}$. Para la evaluación de los tratamientos, se establecieron parcelas de plantas de tomate, con distancia entre surco de $1.5 \mathrm{~m}$ y $0.5 \mathrm{~m}$ entre planta, en total se ubicaron seis surcos de 15 plantas. La parcela útil la constituyeron los dos surcos centrales muestreando un promedio de 20 plantas por tratamientos.

\section{Tratamientos evaluados}

Actara ${ }^{\circledR} 25$ WG (Thiamethoxam). Insecticida sistémico y translaminar, con amplio espectro de acción y rápida penetración. Actúa por contacto e ingestión. Utilizado 
para manejo de insectos chupadores (Bemisia sp, Aphis sp, Oebalus insularis, Aenolamia $s p$ ) de diferentes cultivos. Las dosis recomendadas para insectos plagas en tomate es de 250 $\mathrm{g} \mathrm{ha}^{-1}$ (Syngenta, 2007).

Engeo ${ }^{\circledR}$ 24.7 SC (Thiametoxam 141 g/L y Lambdacihalotrina $106 \mathrm{~g} / \mathrm{L}$ ). Actúa por contacto, por ingestión, y también posee efecto de repelencia y acción anti alimentaria. Es un insecticida indicado para el control de larvas y adultos de insectos masticadores, picadores-chupadores y chupadores (polillas, pulgones, mosquitas blancas). Las dosis recomendadas para insectos plagas en tomate es de 100 $\mathrm{ml} \mathrm{ha}^{-1}$ (Syngenta, 2008).

Insecticida botánico a base de hojas de madero negro (Gliricidia sepium Fabaceae). Se utilizaron $100 \mathrm{~g}$ de hojas G. sepium, se licuaron dejándose reposar por 96 horas en un litro de agua. Antes de utilizarlo se filtró en tela fina y después se combinó con 19 litros de agua en una bomba de mochila, aplicándolo en dosis de $1.2 \mathrm{~kg} \mathrm{ha}^{-1}$.

Insecticida de aceite vegetal + jabón líquido. El tratamiento fue elaborado en base a recomendación propuesta por Funsalprodese (2000), mezclar $180 \mathrm{ml}$ de aceite vegetal, más $90 \mathrm{ml}$ de jabón líquido, esta solución se agregó a 20 litro de agua. Dosis $2.161 \mathrm{ha}^{-1}$ (aceite vegetal) $+1.081 \mathrm{ha}^{-1}$ (jabón líquido).

Insecticida de chile (Capsicum sp) + ajo (Allium sativum) + jabón: Chile y ajo se emplean como insecticida de contacto. Se combinaron $100 \mathrm{~g}$ de frutos de chile, más $100 \mathrm{~g}$ de ajo, se molieron y se combinaron con $20 \mathrm{~g}$ de jabón, todo diluido en un litro de agua. Se dejó reposar por 48 horas. La mezcla se aplicó a 20 litros de agua en una bomba de mochila de 20 litros. Dosis $1.2 \mathrm{~kg} \mathrm{ha}^{-1}$ (chile) $+1.2 \mathrm{~kg} \mathrm{ha}^{-1}$ de (ajo) + $240 \mathrm{~g} \mathrm{ha}^{-1}$ (jabón).

Testigo: Sin aplicaciones de insecticidas.

Las aplicaciones de los tratamientos en evaluación se iniciaron a partir de registrar un umbral igual o mayor a 1 mosca blanca / planta, repitiéndose las veces que fueran encontradas por recuento realizado.

Establecimiento y manejo del ensayo. Se utilizó semilla de tomate híbrido Shanty ${ }^{\circledR}$ (Hazera Seeds, Inc.) y en ambos períodos el manejo del semillero se realizó según Rodríguez y Morales (2007), quienes recomiendan utilizar bandejas de plástico de 96 celdas, depositando una semilla por celda, manteniendo las plántulas dentro de un micro invernadero por un período de 30 días. En la siembra al terreno definitivo se utilizaron densidades poblacionales aproximadamente de 70 plantas por tratamientos $(13,000$ plantas ha-1), en ambos períodos. Para la disminución de competencia inter e intraespecifica entre plantas, se realizaron limpieza de arvenses dentro de los surcos, este manejo se ejecutó de forma manual (chapia) según incidencia de arvenses en el ensayo.

La fertilización de las plantas se realizó utilizando 3 quintales (qq) fertilizante completo (18-46-00), 6 qq de urea $46 \%$ (46-0-0) y 4 qq de Muriato de potasio (0-0-60), las dosis aplicada se distribuyó de acuerdo a la demanda que la planta de tomate requiere $\left(\mathrm{N}=280 \mathrm{~kg}, \mathrm{P}_{2} \mathrm{O}_{5}=160 \mathrm{~kg}, \mathrm{~K}_{2} \mathrm{O}=300 \mathrm{~kg}\right.$ todos en ha-1 ${ }^{-1}$, distribuido en las fases fenológica (Chemonics, 2008; INTA, 2004). Se utilizó riego por inundación de surcos o camellones, se aplicó según criterio del productor. El manejo de enfermedades se realizó con bactericida fungicidas Phyton $27^{\circledR}$ (sulfato de cobre pentahidratado), Carbendazim 50 AGM(carbendazim 2-metoxcarbamoil bencimidazol), Amistar ${ }^{\circledR} 50 \mathrm{WG}$ (azoxystrobina).

\section{Variables evaluadas}

Números de adultos de moscas blancas (B. tabaci) por planta. El recuento de $B$. tabaci, inició a partir de $8 \mathrm{ddt}$ (Tisma, 02/Octubre/09 y Camoapa, 06/Abril/10), realizándose una vez por semana hasta los 65 ddt. Estás se contabilizaron de forma visual, observando en el haz y envés de las hojas de la parte media de las plantas. Se muestrearon 20 plantas por tratamiento, en total se monitorearon 120 plantas por bloque (480 plantas por experimento).

\section{Promedio de mosca blanca / plantas$$
=\frac{\text { total de plantas con sintomas virales }}{\text { total de plantas muestreadas }}
$$

Porcentaje de incidencia de virosis. Para la evaluación de plantas con virus, se utilizó la observación de síntomas, estimando el porcentaje de incidencia que afectaba al cultivo.

La incidencia de virosis: Es el porcentaje de plantas con síntomas virales en cada parcela experimental. Se utilizó la fórmula utilizada por Chavarría, 2004

$\%$ de incidencia de virosis $=\frac{\text { total de plantas con sintomas virales }}{\text { total de plantas muestreadas }} \times \mathbf{1 0 0}$

Porcentaje de severidad de daños de virus. Para la evaluación del grado de afectación de plantas con virus, se utilizó la escala de grado de severidad de daño, estimando el porcentaje de severidad de virus que afectaba al cultivo.

La severidad de virosis: Se utilizó el descriptor porcentaje de severidad planteado por Vanderplank, (1963):

$$
\% \text { severidad de virus }
$$

$=\frac{\text { total de los grados de severidad encontrados }}{\text { número de plantas muestreadas x el grado mas lato de la escala }} \times \mathbf{1 0 0}$ 
Tabla 1. Escala de severidad de virosis (adaptada por JiménezMartínez, 2006)

\begin{tabular}{ll}
\hline Valor de la escala & \multicolumn{1}{c}{ Características } \\
\hline 0 & $\begin{array}{l}\text { No hay síntomas visibles } \\
\text { Débil mosaico y encolochado de la lámina } \\
\text { foliar de las hojas nuevas } \\
\text { Mosaico y encolochado de las hojas } \\
\text { generalizado } \\
\text { Encolochado y deformación de las hojas y } \\
\text { ramas } \\
\text { Enanismo y deformación severa de la planta }\end{array}$ \\
\end{tabular}

Rendimiento total del cultivo de tomate en $\mathrm{kg} \mathrm{ha}^{-1}$. Para conocer el rendimiento en cada tratamiento, se midió el peso de frutos maduros obtenidos de las veinte plantas muestreadas (tratamiento). El peso se obtuvo en libras y luego se transformó a $\mathrm{kg} \mathrm{ha}^{-1}$.

\section{Análisis económico (CYMMIT, 1988)}

Presupuesto parcial. Se tomaron los datos de rendimiento promedio $(\mathrm{R} \chi)$ por tratamientos y se obtuvo el rendimiento ajustado $\left(\mathrm{R}_{\text {ajust }}=10 \%\right.$ de $\left.\mathrm{R} \chi\right)$, luego se calculó el beneficio bruto multiplicando, el $\mathrm{R}_{\text {ajust }}$ por el precio de venta de campo. Para la sumatoria de los costos totales que varían, se estimaron los costos de los insecticidas evaluados más el costo de aplicación de insecticidas. Para obtener el beneficio neto, se restó los costos totales que varían al beneficio bruto de cada tratamiento respectivamente.

Análisis de dominancia. Se efectúa ordenando los tratamientos de menor a mayor total de costos que varían. Un tratamiento es dominado cuando tiene beneficios netos menores o iguales a los de un tratamiento de costos que varían más bajos. Con los rendimientos obtenidos y los precios vigentes en las fechas de cosechas, se determinó el ingreso bruto y los costos reales específicos para cada tratamiento, se realizó el análisis económico para cada uno de los tratamientos; se logró hacer una evaluación comparativa a través del uso de análisis de tasa marginal de retorno.

Tasa de retorno marginal. Resulta de la división del beneficio neto marginal (es decir, el aumento en beneficios netos) y el costo marginal (aumento de los costos que varían), expresada en porcentaje, la tasa de retorno marginal indica, que por cada unidad monetaria que se invierte en adquirir y aplicar un determinado producto en un determinado cultivo, el agricultor recupera la unidad monetaria invertida en dicha actividad, además de obtener unidades monetarias adicionales.
Análisis estadístico de los datos. Para las variables mosca blanca, otros insectos y enemigos naturales, se realizó un análisis de parcelas dividida en el tiempo, en el que se tomó como parcela grande: las fechas de los muestreos y como parcelas pequeñas: los insecticidas evaluados. En las variables incidencia, severidad de virus y rendimiento, se aplicó un análisis de varianza unifactorial. En los casos que se encontró diferencia estadística se utilizó la separación de medias "Duncan $(a=0.05)$ ". Para el análisis de varianza se realizaron transformaciones de datos, para ajustar a los supuestos de ANDEVA. En la variables mosca blanca y otros insectos se utilizó $(\mathrm{y}=\sqrt{ } \mathrm{x}+5)$ y para incidencia de virus $(\theta=\operatorname{arcsen} \sqrt{ } \mathrm{p})$. Para estos análisis se hizo uso el software estadístico InfoStat versión 2009.

\section{RESULTADOS Y DISCUSIÓN}

Fluctuación poblacional de adultos de $B$. tabaci, en el período comprendido de octubre a diciembre 2009. Se observó la presencia de $B$. tabaci a partir de los 8 días después del trasplante (ddt) en todas las parcelas establecidas. La población más alta se encontró en la parcela que correspondió a chile + ajo + jabón con 0.58 mosca / planta y las más bajas en actara y hojas de madero negro con 0.20 y 0.23 mosca / planta respectivamente. A los $16 \mathrm{ddt}$ y $24 \mathrm{ddt}$, las poblaciones se presentaron por debajo de 1 mosca / planta en todos los tratamientos (figura 2).

A los 32 ddt hubo incremento en las poblaciones de mosca blanca en todos los tratamientos evaluados, encontrando el promedio más alto en el tratamiento de hojas de madero negro con 1.30 insectos / planta. Después de realizar una aplicación de los tratamientos, las poblaciones disminuyeron, encontrando la población más baja en hoja de madero negro con 0.24 mosca / planta, en cambio en el tratamiento testigo fue de 0.95 mosca / planta (figura 2).

Las poblaciones más altas de $B$. tabaci en todo el período del cultivo se registraron en los muestreos de los 48, 56 y 64 ddt. En este último muestreo los tratamientos actara con 2.24 mosca / planta y madero negro con 2.63 mosca por planta fueron los menores y el más alto fue chile + ajo + jabón con 4.12 insectos por planta (figura 2). 


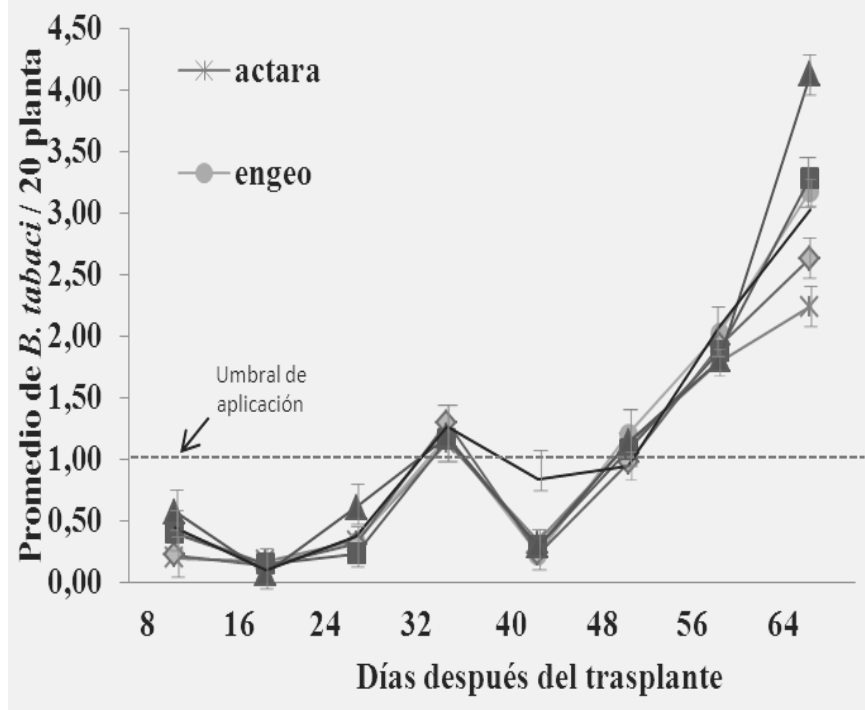

Figura 2. Fluctuación poblacional de adultos de B. tabaci, influenciada 'por los tratamientos en el período comprendido de octubre a diciembre, 2009, Tisma, Masaya.

Fluctuación poblacional de adultos de $B$. tabaci, en el período comprendido de abril a junio de 2010. La incidencia de las poblaciones de B. tabaci en Camoapa, inició a los 8 ddt (06 abril 10), el promedio más alto registrado fue hojas de madero negro con 2.1 mosca / planta y el promedio más bajo engeo con 1.2 mosca / planta. Entre el período de los 16 ddt (12 abril 10) hasta los 62 ddt (28 junio 10), el tratamiento testigo presentó las poblaciones de B. tabaci más altas de todos los tratamientos evaluados en el cultivo de tomate. El pico más alto de la población fue a los 32 ddt. Entre los tratamientos con menores poblaciones de mosca blanca, el tratamiento de aceite vegetal + jabón líquido registró poblaciones desde 2.4 mosca / planta (16ddt) disminuyendo hasta 1.1 mosca / planta (62 ddt). Él segundo tratamiento con bajas poblaciones fue hojas de madero negro con promedios de 1.2 mosca / planta a los 62 ddt (Figura 3).

Al realizar el análisis de varianza a las poblaciones de mosca blanca encontradas en Tisma (2009) presentaron diferencias significativas para la fechas de muestreo $(P=0.0001)$ y los tratamientos $(P=0.007)$. La prueba de separación de medias (Duncan, $\alpha=0.05$ ) muestra los menores promedios de mosca blanca en el tratamiento actara con 0.81 \pm 0.14 insectos por planta ubicándose en una categoría, una segunda categoría identificada fue hoja de madero negro con $0.89 \pm 0.16$. Los promedios más altos fueron el tratamiento testigo con $1.01 \pm 0.18$ y chile + ajo + jabón con $1.13 \pm 0.23$, los cuales difieren de los tratamientos mencionados al inicio (tabla 2).

El análisis de varianza a las fluctuaciones poblacionales de mosca blanca en Camoapa (2010) muestra diferencia significativa en las fechas $(P=0.0001)$, y en los tratamientos $(P=0.0001)$. La prueba de Duncan $(\alpha=0.05)$, indica que el tratamiento con las menores poblaciones de mosca blanca fue actara con $1.58 \pm 0.11$ mosca por planta, seguido de engeo con $1.69 \pm 0.14$ mosca por planta, el insecticida aceite vegetal + jabón líquido con promedio $1.96 \pm 0.15$ mosca por planta. El insecticida a base de hojas de madero negro y chile + ajo + jabón presentaron los mayores valores con $1.96 \pm 0.14$ y $2.02 \pm 0.18$ moscas por planta respectivamente. El más alto promedio lo presentó el testigo con $2.25 \pm 0.25$ mosca por planta.

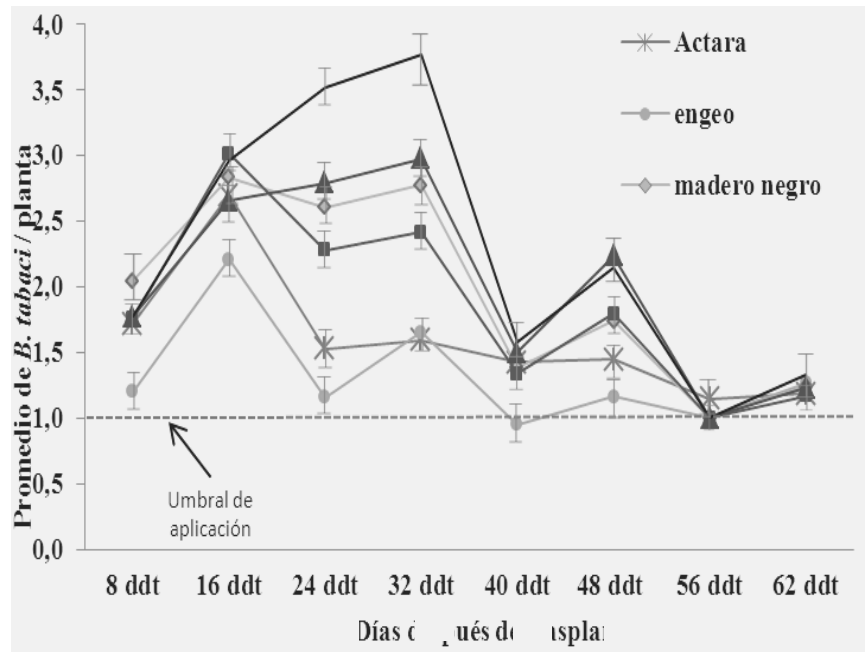

Figura 3. Fluctuación poblacional de adultos de B. tabaci, influenciada por los tratamientos en el período comprendido de abril a junio, 2010, Camoapa, Boaco.

Al observar la dinámica poblacional de adultos de mosca blanca, se nota que existe diferencias en los promedios registrados. En la localidad de Tisma (2009), se observó poblaciones de $B$. tabaci más bajos que en Camoapa (2010). Estas diferencias pudieron deberse a que el ensayo se estableció en la época de invierno (postrera) en Tisma, en cambio en Camoapa fue en época de riego. Jiménez - Martínez (2009), menciona que el clima juega un papel importante sobre los procesos vitales de las poblaciones de insectos. CATIE (1990) hace referencia que mosca blanca es un insecto que presenta altas poblaciones en época seca.

Al hacer una valoración del efecto de los tratamientos sobre las poblaciones de mosca blanca en ambas localidades, el insecticida químico (actara), ejerce un efecto significativo, al mantener las poblaciones bajas. Hay que mencionar que los insecticidas químicos dan una pronta y eficiente respuesta a la incidencia de insectos plagas, aunque Jiménez - Martínez (2009), refiere que el uso de estos productos trae implicaciones ambientales, agroecológicas y sobre la salud del hombre. El insecticida antes mencionados tiene como ingrediente activo (Tiametoxam) quien ha sido evaluado como un producto moderadamente toxico en los mamíferos, pero altamente en abejas (MAVDT, 2009). 
Tabla 2. Comparación estadística (Duncan al $5 \%$ ) de las medias poblacional de $B$. tabaci, por tratamientos en parcela de tomate en Tisma, Masaya, 2009 y Camoapa, Boaco, 2010

\begin{tabular}{|c|c|c|c|c|}
\hline \multirow[b]{2}{*}{ Tratamientos } & \multicolumn{2}{|c|}{ Tisma, 2009} & \multicolumn{2}{|c|}{ Camoapa, 2010} \\
\hline & Medias $\pm \mathrm{EE}$ & Categoría & Medias $\pm \mathrm{EE}$ & Categoría \\
\hline actara & $0.81 \pm 0.14$ & a & $1.58 \pm 0.11$ & $\mathrm{a}$ \\
\hline madero negro & $0.89 \pm 0.16$ & $a b$ & $1.96 \pm 0.14$ & $\mathrm{c}$ \\
\hline aceite vegetal+jabón líquido & $0.96 \pm 0.19$ & $a b c$ & $1.85 \pm 0.15$ & $\mathrm{bc}$ \\
\hline engeo & $0.99 \pm 0.19$ & bc & $1.69 \pm 0.14$ & $a b$ \\
\hline testigo & $1.01 \pm 0.18$ & $\mathrm{bc}$ & $2.25 \pm 0,25$ & d \\
\hline chile+ajo+jabón & $1.13 \pm 0.23$ & $\mathrm{c}$ & $2.02 \pm 0.18$ & $\mathrm{c}$ \\
\hline C.V $=$ & $34.30 \%$ & & $17.98 \%$ & \\
\hline $\mathrm{P}=$ & 0.007 & & 0.0001 & \\
\hline $\mathrm{Fc}, \mathrm{gle}=$ & $3.39 ; 105$ & & $15.99 ; 105$ & \\
\hline
\end{tabular}

$\mathrm{EE}=$ error estándar $\mathrm{CV}=$ Coeficiente de variación; $\mathrm{Pr}=$ probabilidad (según Duncan); $\mathrm{Fc}=$ fisher calculado; gle $=$ grado de liberta del error.

Comparación de los promedios de incidencia de virosis. El análisis de varianza realizado a los promedios registrados de porcentaje incidencia de virosis en los tratamientos evaluados en Tisma (2009), mostró que hay diferencia significativa de 0.01 , con un coeficiente de variación de $60.11 \%$. En la tabla 3 , se observan las categorías estadísticas conformadas por la separación de medias según Duncan $(\alpha=0.05)$, el porcentajes de incidencia de virus más alto fue en chile + ajo + jabón con $23.75 \pm 2.39 \%$, el más bajo fue en plantas manejadas con engeo con $3.75 \%$ de incidencia y un segundo categoría de tratamientos con porcentajes bajos fueron aceite vegetal + jabón líquido, hoja de madero negro y actara.
El ANDEVA realizado a los promedios de porcentaje de incidencia de virus en los tratamientos evaluados en Camoapa (2010), presentó diferencia significativa igual a 0.05 y un coeficiente de variación de $35.5 \%$ (tabla 3 ). La separación de medias de Duncan, separó en tres categorías a los tratamientos evaluados. Los menores porcentajes de incidencia fueron observados en los tratamientos engeo $(28 \%)$, actara $(31 \%)$ y chile + ajo + jabón $(31 \%)$. En el tratamiento aceite vegetal + jabón líquido se registró un promedio de incidencia de virosis del $38 \%$. El testigo tuvo el promedio de incidencia de virosis (56\%) más alto (tabla 3 ).

Tabla 3. Comparación estadística (Duncan al $5 \%$ ) de los promedios de porcentajes de incidencia de virosis por tratamiento en parcela de tomate en Tisma, (2009) y Camoapa, (2010)

Incidencia de virus x Localidad

\begin{tabular}{lcccc}
\hline & \multicolumn{2}{c}{ Tisma, 2009 } & \multicolumn{2}{c}{ Camoapa, 2010 } \\
\hline Tratamientos & Medias \pm EE (\%) & Categoría & Medias \pm EE (\%) & Categoría \\
\hline engeo & $3.75 \pm 1.25$ & $\mathrm{a}$ & $28.00 \pm 0.03$ & $\mathrm{a}$ \\
aceite vegetal+jabón líquido & $5.00 \pm 2.89$ & $\mathrm{ab}$ & $38.00 \pm 0.1$ & $\mathrm{ab}$ \\
madero negro & $6.25 \pm 3.15$ & $\mathrm{ab}$ & $48.00 \pm 0.1$ & $\mathrm{ab}$ \\
actara & $10.00 \pm 2.89$ & $\mathrm{ab}$ & $31.00 \pm 0.02$ & $\mathrm{a}$ \\
testigo & $16.25 \pm 6.25$ & $\mathrm{bc}$ & $56.00 \pm 0.07$ & $\mathrm{~b}$ \\
chile+ajo+jabón & $23.75 \pm 2.39$ & $\mathrm{c}$ & $31.00 \pm 0.04$ & $\mathrm{a}$ \\
& & & & 35.5 \\
CV $(\%)$ & 68.11 & & 0.05 & $2.50 ; 15$ \\
P $\leq 0.05$ & 0.01 & & &
\end{tabular}

$\mathrm{EE}=$ error estándar $\mathrm{CV}=$ Coeficiente de variación; $\mathrm{Pr}=$ probabilidad (según Duncan $\alpha=0.05$ ); Fc= fisher calculado; gle $=$ grado de liberta del error. 
Se observó que los resultados de Tisma (2009) presentaron promedios de incidencia de virus más bajos que los reportados por Jiménez - Martínez (2007), quién declaró que al hacer uso de protección de semillero en micro invernadero, los porcentajes de incidencia de virus a los 60 ddt pueden ser de $14.00 \%$. Al hacer la comparación con los resultados de Camoapa (2010), es evidente que los porcentajes de incidencia de virus fueron mayores, aunque al realizar la separación de medias de Duncan, los tratamientos se ubican en similar categoría para ambas localidades (Tisma, 2009 y Camoapa, 2010). El alto porcentaje de incidencia de virus en Camoapa, está relacionado a las altas poblaciones de mosca blanca. Al respecto Holt et al., (2008), menciona que la presencia de mosca blanca en cantidades y tiempo después del trasplante es directamente proporcional al porcentaje de incidencia de virus en plantas de tomate.
Comparación de los promedios de porcentajes de severidad de virosis. A los promedios de porcentaje de severidad de virosis obtenidos en Tisma (2009), se realizó un análisis de varianza, encontrando diferencias significativas entre tratamientos $(P=0.004)$. Los menores porcentajes de severidad $(2.5 \% \pm 0.88 ; 2.5 \% \pm 1.44)$ se encontraron en los tratamientos engeo y aceite vegetal + jabón líquido respectivamente y el mayor $(14.38 \pm 1.20 \%)$ se encontró en el chile + ajo + jabón (tabla 4).

El análisis de varianza realizado a los porcentaje de severidad de virosis registrados en tratamientos evaluados en Camoapa (2010), mostró que existe diferencia entre tratamientos a una probabilidad de 0.07 y un coeficiente de variación de $71.32 \%$. La separación de media según "Duncan", clasificó a tres Categoría estadísticos, ubicándose como los menores porcentaje de severidad a actara con 7.51 $\% \pm 2.22$ y chile + ajo + jabón con $7.98 \% \pm 2.79$ y los más altos hojas de madero negro con $17.20 \% \pm 4.85$ y testigo con $15.34 \% \pm 3.89$ (tabla 4 ).

Tabla 4. Comparación estadística (Duncan al $5 \%$ ) de los promedios de porcentajes de severidad de virus por tratamiento en parcela de tomate en Tisma (2009) y Camoapa (2010)

Severidad de virus x Localidad

\begin{tabular}{|c|c|c|c|c|}
\hline \multirow[b]{2}{*}{ Tratamientos } & \multicolumn{2}{|c|}{ Tisma, 2009} & \multicolumn{2}{|c|}{ Camoapa, 2010} \\
\hline & Medias \pm EE $(\%)$ & Categoría & Medias \pm EE $(\%)$ & Categoría \\
\hline engeo & $2.5 \pm 0.88$ & $\mathrm{a}$ & $9.22 \pm 2.37$ & $\mathrm{ab}$ \\
\hline aceite veg+jabón líquido & $2.5 \pm 1.44$ & $\mathrm{a}$ & $9.03 \pm 2.35$ & $\mathrm{ab}$ \\
\hline madero negro & $4.6 \pm 1.56$ & $a b$ & $17.20 \pm 4.85$ & $\mathrm{~b}$ \\
\hline actara & $5.00 \pm 0.72$ & $a b$ & $7.51 \pm 2.22$ & $\mathrm{a}$ \\
\hline testigo & $10.00 \pm 3.95$ & $\mathrm{bc}$ & $15.34 \pm 3.89$ & $\mathrm{~b}$ \\
\hline chile+ajo+jabón & $14.38 \pm 1.20$ & $\mathrm{c}$ & $7.98 \pm 2.79$ & a \\
\hline $\mathrm{CV}(\%)$ & 63.78 & & 71.32 & \\
\hline $\mathrm{P} \leq 0.05$ & 0.004 & & 0.07 & \\
\hline Fc; gle & $3.61 ; 15$ & & $3.27 ; 15$ & \\
\hline
\end{tabular}

$\mathrm{EE}=$ error estándar $\mathrm{CV}=$ Coeficiente de variación; $\mathrm{P}=$ probabilidad (según Duncan); $\mathrm{Fc}=$ fisher calculado;

gle $=$ grado de liberta del error.

Tisma (2009) se encontró $14.38 \%$ de severidad de virus, esté promedio fue menor a los encontrados por Rodríguez y Morales (2007), quienes registraron porcentajes de severidad de $38 \%$ en la etapa de campo. Camoapa, 2010 los promedios más alto fue de $23 \%$ severidad de virus, promedio más bajo que los reportados por Zelaya (2004), quien menciona que en el departamento de Boaco, los porcentaje de severidad registrados es hasta de un $55 \%$.

Rendimiento ( $\mathrm{kg} \mathrm{ha}^{-1}$ ). Se compararon los rendimientos obtenidos en los tratamientos evaluados en Tisma (2009) y Camoapa, 2010. En Tisma, se identificaron cinco categoría estadísticos $(P=0.01, \mathrm{CV}=23.39 \%)$. Los promedios de los rendimientos $\left(\mathrm{kg} \mathrm{ha}^{-1}\right)$, muestran al tratamiento de engeo con $26581 \mathrm{~kg} \mathrm{ha}^{-1}$ con el mayor rendimiento. El tratamiento con madero negro en una segunda categoría con $5277 \mathrm{~kg}$ ha ${ }^{1}$, Luego el tratamiento de aceite vegetal + jabón líquido con $24429 \mathrm{~kg} \mathrm{ha}^{-1}$ y chile + ajo + jabón con $24017 \mathrm{~kg} \mathrm{ha}^{-1}$, los cuales no difieren estadísticamente entre ellos. En una cuarto categoría se ubicó actara $\left(22148 \mathrm{~kg} \mathrm{ha}^{-1}\right)$ y luego el testigo $\left(21467 \mathrm{~kg} \mathrm{ha}^{-1}\right)$.

En el ensayo de Camoapa (2010), los rendimientos fueron inferiores. La separación de medias según Duncan determino cuatro categorías estadísticas. Los mayores 
rendimientos lo presentaron engeo (18953 $\left.\mathrm{kgha}^{-1}\right)$ y madero negro $\left(18107 \mathrm{~kg} \mathrm{ha}^{-1}\right)$. En una segunda se ubicaron aceite vegetal + jabón líquido con $17433 \mathrm{~kg} \mathrm{ha}^{-1}$; chile + ajo + jabón $\left(16621 \mathrm{~kg} \mathrm{ha}^{-1}\right)$. El tratamiento a base de actara $\left(15973 \mathrm{~kg} \mathrm{ha}^{-}\right.$ 1) se ubicó en una nueva categoría, y el testigo con $14216 \mathrm{~kg}$ ha $^{-1}$ con los menores rendimientos en cuarta categoría..

La disminución de los rendimientos por localidad podría deberse a los cambio de ambientes, aunque las variantes entre los tratamientos están relacionadas a la incidencia de virosis. (Lastra, 1993) menciona que la presencia de virus pueden reducir los rendimientos de tomate hasta en $100 \%$ y si son adquiridos (virus) 14 días antes de expresarse en la planta, los rendimientos se reducen en 24 \% (Acuña, 1993).
Comparación económica de los tratamientos, Tisma (2009) y Camoapa (2010). A través de una análisis económico, se comparó los tratamiento evaluados para el manejo de mosca blanca-geminivirus en Tisma, 2009. Se aplicó la metodología según CIMMYT (1988). En la tabla 5 , se presenta el presupuesto parcial realizado en Tisma (2009), en él se observa que los mayores costos variables se obtuvieron en los tratamientos actara con U\$ 333.16 ha $^{-1}$, aceite vegetal + jabón líquido con U\$240.36 ha- ${ }^{-1}$ y engeo con U\$ $163.76 \mathrm{ha}^{-1}$. Los tratamientos con menor costo variables de manejo fueron chile + ajo + jabón con U\$ 111.96 ha $^{-1}$ y hojas de madero negro con U\$ $56.07 \mathrm{ha}^{-1}$. Los mayores beneficios neto se obtuvieron en los tratamientos engeo con U\$ $12,063.5$ ha $^{-1} \mathrm{y}$ hojas de madero negro con U\$ 11,571.33 ha $^{-1}$

Tabla 5. Presupuesto parcial (U\$) de los tratamientos evaluados en los períodos comprendidos entre octubre a diciembre, 2009, Tisma, Masaya

\begin{tabular}{|c|c|c|c|c|c|c|}
\hline Concepto & actara & engeo & $\begin{array}{l}\text { madero } \\
\text { negro }\end{array}$ & $\begin{array}{l}\text { aceite veg+ } \\
\text { jabón }\end{array}$ & $\begin{array}{l}\text { chile+ajo } \\
\text { +jabón } \\
\text { líquido }\end{array}$ & testigo \\
\hline Rendimiento ajustado $(10 \%)\left(\mathrm{kg} \mathrm{ha}^{-1}\right)$ & 22148 & 26581 & 25277 & 24429 & 24017 & 21467 \\
\hline Precio venta en campo U\$ kg-1 & 0,46 & 0,46 & 0,46 & 0,46 & 0,46 & 0,46 \\
\hline Ingreso bruto (U\$ ha-1) & 10188 & 12227 & 11627 & 11237 & 11048 & 9875 \\
\hline Costo de insecticidas U\$ ha ${ }^{-1}$ & 70 & 27 & 5 & 47 & 14 & 0 \\
\hline Costos de jornal / aplicaciones U\$ ha ${ }^{-1}$ & 14 & 14 & 14 & 14 & 14 & 0 \\
\hline $\mathrm{N}^{\mathrm{o}}$ aplicaciones & 4 & 4 & 3 & 4 & 4 & 0 \\
\hline Costos totales de insecticidas $\mathrm{U} \$ \mathrm{ha}^{-1}$ & 279 & 109 & 15 & 186 & 58 & 0 \\
\hline $\begin{array}{l}\text { Costos totales de aplicación } \\
\text { de insecticidas U\$ ha-1 }\end{array}$ & 54 & 54 & 41 & 54 & 54 & 0 \\
\hline $\begin{array}{l}\text { Costos totales que varían } \\
\left(\mathrm{U} \$ \mathrm{ha}^{-1}\right)\end{array}$ & 333 & 164 & 56 & 240 & 112 & 0 \\
\hline Beneficio neto (U\$ ha $^{-1}$ ) & 9855 & 12064 & 11571 & 10997 & 10936 & 9875 \\
\hline
\end{tabular}

Presupuesto parcial (U). El presupuesto parcial elaborado a los tratamientos evaluados en Camoapa (2010) para el manejo de mosca blanca (tabla 6). Entre las diferencias que se notan con respecto al experimento de Tisma (2009) están, el precio de venta de campo (U\$ $0.72 \mathrm{~kg}^{-1}$ ) y el número de aplicaciones realizadas por tratamientos. Esto influyo para que los costos totales que varían también aumentaran. Los beneficios brutos más altos fueron engeo con U\$13646.16 $\mathrm{ha}^{-1}$, hojas de madero negro con U\$ $13037.04 \mathrm{ha}^{-1}$.

Los menores costos variables registrados fueron en los tratamientos hoja de madero negro con U\$ 136.50 ha $^{-1} \mathrm{y}$ chile + ajo + jabón con U\$208.04 hä ${ }^{-1}$.
Análisis de dominancia (U\$). Después de haber realizado el presupuesto parcial, para identificar los costos variables de los tratamientos evaluados, se procedió a ejecutar el análisis de dominancia. El ordenamiento de los tratamientos inicio con el testigo por ser el menor de los costos variable (tabla 7). El análisis indicó que los tratamientos testigo, chile + ajo + jabón, actara y aceite vegetal + jabón líquido resultaron dominados por los tratamientos hojas de madero negro y engeo. Ya que presentaron lo más altos beneficios netos 
Tabla 6. Presupuesto parcial (U\$) de los tratamientos evaluados en los períodos comprendidos entre abril a junio, 2010, Camoapa, Boaco

\begin{tabular}{lrrrrrr}
\hline Concepto & actara & engeo & $\begin{array}{c}\text { madero } \\
\text { negro }\end{array}$ & $\begin{array}{c}\text { aceite veg+ } \\
\text { jabón }\end{array}$ & $\begin{array}{c}\text { chile+ajo } \\
\text { +jabón } \\
\text { líquido }\end{array}$ & testigo \\
& & & & & &
\end{tabular}

* Precio oficial del dólar: C\$21.30 (Junio, 2010). Fuente: Banco Central de Nicaragua

** Precio del producto al momento de la cosecha (0.72 U\$ $/ \mathrm{kg})$.

Tabla 7. Análisis de dominancia de los tratamientos evaluados en Tisma (2009) y Camoapa, (2010)

\begin{tabular}{|c|c|c|c|c|c|c|}
\hline \multirow[b]{2}{*}{ Tratamiento } & \multicolumn{3}{|c|}{ Tisma, 2009} & \multicolumn{3}{|c|}{ Camoapa, 2010} \\
\hline & $\begin{array}{l}\text { CTV } \\
\text { U\$ ha-1 }\end{array}$ & $\begin{array}{c}\text { BN } \\
\text { U\$ ha-1 }\end{array}$ & Categ & $\begin{array}{l}\text { CTV } \\
\text { U\$ ha-1 }\end{array}$ & $\begin{array}{c}\text { BN } \\
\text { U\$ ha-1 }\end{array}$ & Categ \\
\hline Testigo & 0 & 9875 & $\mathrm{D}$ & 0 & 10236 & $\mathrm{D}$ \\
\hline Madero negro & 56 & 11571 & ND & 137 & 12901 & ND \\
\hline Chile+Ajo+Jabón & 112 & 10936 & $\mathrm{D}$ & 208 & 11759 & $\mathrm{D}$ \\
\hline Engeo & 164 & 12064 & ND & 213 & 13433 & ND \\
\hline Aceite Vegetal+ Jabón Líquido & 240 & 10997 & $\mathrm{D}$ & 455 & 12097 & $\mathrm{D}$ \\
\hline Actara & 333 & 9855 & $\mathrm{D}$ & 610 & 10891 & $\mathrm{D}$ \\
\hline
\end{tabular}

ND: No dominado, D: Dominado.

El análisis de dominancia realizado al presupuesto parcial del ensayo establecido en Camoapa (2010), se presenta en la tabla 7, por la comparación de los tratamientos de menor costos variables con los mayores beneficios neto, se observa que los tratamientos engeo con costo variable de U\$213.00 $\mathrm{ha}^{-1}$ y un beneficio neto de U\$13433.16 ha ${ }^{-1}$ y hojas de madero negro con costo variable U\$136.50 $\mathrm{ha}^{-1}$ y beneficio neto de U\$12900.54 ha-1 no son dominados.
Análisis de tasa de retorno marginal (TRM). Al comparar los costos de varían del tratamiento engeo con los costos que varían del tratamiento de hoja de madero negro la diferencia fue de U\$ 107.69 ha $^{-1}$ mayor para engeo, pero esa inversión permite obtener una tasa de retorno marginal de $457.00 \%$. Por tanto el productor al utilizar engeo como tratamiento de manejo del complejo mosca blanca-geminivirus recupera su inversión, más un beneficio adicional de $328.58 \%$. 
Tabla 8. Análisis de tasa de retorno marginal (TRM) de los tratamientos evaluados en Tisma (2009) y Camoapa (2010)

\begin{tabular}{|c|c|c|c|c|c|}
\hline $\begin{array}{l}\text { Tratamientos } \\
\text { no dominados }\end{array}$ & $\begin{array}{l}\text { CTV } \\
\text { U\$ ha- }\end{array}$ & $\begin{array}{c}\text { Costo } \\
\text { marginal } \\
\text { U\$ ha-1 }\end{array}$ & $\begin{array}{c}\text { BN } \\
\text { U\$ ha-1 }\end{array}$ & $\begin{array}{c}\text { Beneficio } \\
\text { marginal } \\
\mathrm{US} \mathrm{ha-1}\end{array}$ & TRM \\
\hline \multicolumn{6}{|l|}{ Tisma 2009} \\
\hline Madero negro & 56 & & 11571 & & \\
\hline Engeo & 164 & 108 & 12064 & 492 & 4.57 \\
\hline \multicolumn{6}{|l|}{ Camoapa, 2009} \\
\hline Madero negro & 137 & & 12901 & & \\
\hline Engeo & 213 & 77 & 13433 & 533 & 6.96 \\
\hline
\end{tabular}

En la tabla 8, se presentan los tratamientos que no fueron dominados, por lo que se procedió a realizar el análisis de la tasa de retorno marginal, la cual nos orienta a utilizar el manejo con engeo por tener una tasa de retorno marginal igual a $696.00 \%$.

La mayor rentabilidad la presenta el tratamiento con engeo. El dominio de este insecticida esta en relación a los altos beneficios netos obtenidos, aunque valorando el efecto de las alternativas de origen botánica, se pueden identificar que la relación beneficio costo es mayor para el caso de hoja de madero negro (Gliricidia sepium) en relación con el engeo. Martínez (2005) hace mención que las alternativas de manejo de Bemisia tabaci con productos botánicos y sintéticos, podría ser una alternativa para el agricultor siempre que la disminución en las pérdidas de la producción causadas por la virosis no represente altos costos de producción. Con la identificación de efecto positivo de algunos insecticidas de origen vegetal, se pueden utilizar en una estrategia de manejo ecológico de plagas (MEP) como lo menciona, Brechelt (2004), las posibilidades del MEP pueden ser muchas, si es que se potencian y combinan adecuadamente el conjunto de técnicas y prácticas posibles de implementar en un agro ecosistema. Más aún si se pretende regular la dinámica poblacional de los insectos y otros organismos potencialmente nocivos.

\section{REFERENCIAS BIBLIOGRÁFICAS}

Acuña, W. 1993. Efecto de la infección de un Geminivirus sobre el rendimiento del cultivo de tomate en diferentes estados del desarrollo de la planta. Tesis Ing. Agr. Turrialba, CR, Universidad de Costa Rica.

AMUNIC (Asociación de Municipios de Nicaragua). 2005. Municipios: Caracterización de municipios de Masaya (en línea). Managua, NI. Consultado el 09 de Agosto del 2007. Disponible en http//www.amunic.org/

Brechelt, A. 2004. Manejo Ecológico de Plagas y Enfermedades. Red de Acción en Plaguicidas y sus Alternativas para América Latina (RAP-AL). Fundación Agricultura y Medio Ambiente (FAMA). R.D.

CATIE, 1990. Guía para el manejo integrado de plagas del cultivo de Tomate. Turrialba. CR. 138 pag. Serie técnica, Informe Técnico $\mathrm{N}^{\circ} 151$.

Chavarría, S. 2004. Evaluación de cinco variedades de tomate (Lycopersicum esculentun Mill.) en relación al complejo mosca blanca-geminivirus bajo infecciones naturales en la zona del pacifico de Nicaragua. Tesis de Ingeniero Agrónomo. Facultad de Agronomía. Universidad Nacional Agraria. Managua, NI.

CHEMONICS INTERNATIONAL. 2008. Manual del cultivo de tomate. Programa de diversificación hortícola proyecto de desarrollo de la cadena de valor y conglomerado agrícola. Cuenta Reto del milenio. NI.

CIMMYT. 1988. La formulación de recomendaciones a partir de datos agronómicos: Un manual metodológico de evaluación económica. Edición completamente revisada. México D.F., MX.

EDA (Entrenamiento y Desarrollo de Agricultores). 2006. Boletín de mercadeo: "conocer su producto tomate". FHIA. HN.

FAS / USDA (Foreign Agricultural Service / Horticultural \& Tropical Products Division). 2003. Processed Tomato Products Outlook and Situation in Selected Countries. 7 p.

Fauquet, DP. 2000. Virus taxonomy seventh report of the international comite on taxonomy of virosesacademi express. p.1126.

FINANCIERA RURAL, 2009. Monografía tomate rojo (Jitomate). Dirección General Adjunta de Planeación Estratégica y Análisis Sectorial.

Flores, G; Hilje, L; Mora, G; Carballo, M. 2008. Antifeedant activity of botanical crude extracts and their fractions on Bemisia tabaci Genn(Homoptera: Aleyrodidae) adults Sechiumpittieri(Cucurbitaceae). Department of Agriculture and Agroforestry Tropical Agricultural Research and Higher Education Center (CATIE). Turrialba, CR In:. Rev. Biol. Trop. 56 (4): 21152129.

FUNSALPRODESE (Fundación Salvadoreña para la promoción social y el desarrollo económico). 2000. Elaboración de plaguicidas orgánicos. San Salvador, SV. 
Gina, B; Luko, H; Vanessa, B; Cartín, V; Calvo, M. 2009. Actividad fagodisuasiva de las plantas Tithonia diversifolia y Montanoa hibiscifolia (Asteraceae) sobre adultos del insecto plaga Bemisia tabaci Genn (Homoptera: Aleyrodidae). Consultados en http://web.ebscohost.com/ehost/pdfviewer/pdfviewer?hid=8\&sid=974acb55-cd2b-4a62-a64e-c1d4fd68dab2 $\% 40$ sessionmgr10\&vid $=6$

Guachambala, M. 2007. Identificación de biotipos A, B y Q de Bemisia tabaci y la especie Trialeurodes vaporariorum en zona de producción hortícola de Honduras. Proyecto especial presentado como requisito parcial para optar al título de Ingeniero Agrónomo en el grado Académico de Licenciatura Carrera de Ciencia y Producción Agropecuaria. Zamorano.

Holt, J; Pavis, C; Marquier, M; Chancellor, TCB; Urbino, C; Boissot, N. 2008. Insect-screened cultivation to reduce the invasion of tomato crops by Bemisia tabaci: modelling the impact on virus disease and vector Agricultural and Forest Entomology (2008), 10, 61-67.

INIFOM (Instituto Nicaragüense de Fomento Municipal). 2011. Municipios de Boaco: Ficha Municipal de Camoapa. Consultada 20 de Agosto de 2011. Disponible en http://www.inifom.gob.ni/municipios/documentos/BOACO/camoapa.pdf

INTA. 2004. Manejo Integrado de Plagas "Cultivo de tomate” Guía MIP. Managua, NI. 1 ed. 64 pg.

Jimenez-Martinez, E. 2007. Evaluación de alternativas de semilleros de tomate (Lycopersicum esculentum Mill) contra el ataque del complejo mosca blanca (Bemisia tabaci, Gennadius)-Geminivirus. La Calera No 6 . UNA. NI.

2008. Evaluación de alternativas de protección física y química de semillero de chiltoma (Capsicum annum, L.) contra el ataque del complejo mosca blanca (Bemisia tabaci, Genn.)-Geminivirus. La Calera, año 8, no 11, pág. 29-38. UNA. NI.

2009. Manejo Integrado de Plagas. Dirección de investigación, extensión y posgrado. UNA. Managua. NI.

MAVDT (Ministerio Ambiente, Vivienda y Desarrollo Territorial). 2009. "Dictamen técnico ambiental para el producto formulado centric ${ }^{\circledR} 75 \mathrm{sg}$, a partir del ingrediente activo grado técnico Tiametoxam dentro del trámite administrativo de registro". Resolución número 0390. República de Colombia. Consultado en:

http://www.minambiente.gov.co/documentos/res_0390_270209.pdf

Martínez, J. 2005. Evaluación de productos sintéticos y bioplaguicidas para el control de mosca blanca (Bemisia tabaci) y gusano del fruto (Helicoverpa zea) en el cultivo del tomate (Lycopersicum esculentum); Sébaco, Nicaragua. Programa de enseñanza para el desarrollo y la conservación escuela de posgrado. Centro agronómico tropical de investigación y enseñanza. CR.

MIFIC (Ministerio de fomento, industria y comercio). 2007. Ficha de Tomate. Gobierno de Reconciliación Nacional. NI.

Lowe, S; Browne M; Boudjelas S; de Poorter, M. 2000. 100 de las Especies Exóticas Invasoras más dañinas del mundo Una selección del Global Invasive Species Database. Publicado por el Categoría Especialista de Especies Invasoras (GEEI), un Categoría especialista de la Comisión de Supervivencia de Especies (CSE) de la Unión Mundial para la Naturaleza (UICN), 12pp. Primera edición,

en inglés, sacada junto con el número 12 de la revista Aliens, Diciembre 2000. Versión traducida y actualizada: Noviembre 2004.

Peralta, IE; Spooner, DM, 2007. History, origin and early cultivation of tomato (Solanaceae). pp 1-27. In: Genetic Improvement of Solanaceous Crops, Vol. 2: Tomato. M.K. Razdan and A.K. Mattoo (eds.), Science Publishers, Enfield, USA.

Rayo, M. 2001. Caracterización biológica transmitido por mosca blanca (Bemisia tabaci Genn.) en el cultivo del tomate (Lycopersicum esculentun Mill) en el municipio de Santa Lucía, Boaco. Trabajo de diploma para optar a Ingeniero Agrónomo Departamento de protección vegetal, Facultad de Agronomía, Universidad Nacional Agraria Managua. NI.

Rodriguez, V; Morales, J. 2007. Evaluación de alternativas de protección física y química de semilleros de tomate (Lycopersicum esculentum Mill) contra el ataque del complejo mosca blanca (Bemisia tabaci, Gennadius) - Geminivirus y su efecto en el rendimiento, en el municipio de Tisma, Masaya. Trabajo de diploma para optar a Ingeniero Agrónomo

Departamento de protección vegetal, Facultad de Agronomía, Universidad Nacional Agraria. Managua, NI.

Smith, A. F. 1994. The tomato in America: early history, culture, and cookery. University of South Carolina Press, Columbia, S.C, USA. SYNGENTA CROP PROTECTION. 2007.19/DIC/07 ACTARA® 25 WG. INSECTICIDA - Gránulos Dispersables en Agua (WG). Composición Thiametoxam $250 \mathrm{~g} / \mathrm{kg} \quad(25 \% \mathrm{p} / \mathrm{p}) \quad$ Sustancias auxiliares e inertes hasta completar 1 kilo 3-(2-cloro-tiazol-5-ilmetil)-5-metil-(1,3,5)oxadiazinan-4-iliden-N-nitroamina. Etiqueta, 19/dic/2007. Autorización del Servicio Agrícola y Ganadero $\mathrm{N}^{\circ} 1593$. Pag 14.

SYNGENTA CROP PROTECTION. 2008. ENGEO® 247 SC. INSECTICIDA - Suspensión Concentrada (SC). Composición Thiametoxam $141 \mathrm{~g} / \mathrm{L}(14,1 \%$ p/v); Lambda-cihalotrina $106 \mathrm{~g} / \mathrm{L}$ (10,6\% p/v). Etiqueta, 01/dic/2008. Autorización del Servicio Agrícola y Ganadero N 1701. Pag 10.

Vanderplank, EJ. 1963. Plant diseases: Epidemiology and control. New York. Academic press. 69 p.

Zamora, M; Padilla, D; Sediles, A; Monterrey, J; Castillo, P. 2002. Informe Nicaragua en x taller iberoamericano y del caribe sobre moscas blancas y geminivirus. Rev. Protección veg. vol. 17 no. 2 (2002): 75-126.

Zelaya, M. 2004. Evaluación del comportamiento de cinco materiales de tomate (Lycopersicum esculentum Mill) ante el ataque del complejo mosca blanca - geminivirus en la región central de país. Trabajo de diploma para optar a Ingeniero Agrónomo Departamento de protección vegetal, Facultad de Agronomía, Universidad Nacional Agraria. Managua, NI.

Zúñiga, C; Ramírez, P. 2002. Los Geminivirus, patógenos de importancia mundial. Manejo integrado de plagas y Agroecología. Turrialba, CR. Pág. 25-33. 